\title{
Treosulfan Pharmacokinetics and its Variability in Pediatric and Adult Patients Undergoing Conditioning Prior to Hematopoietic Stem Cell Transplantation: Current State of the Art, In-Depth Analysis, and Perspectives
}

\author{
Michał Romański ${ }^{1}$ (D) Jacek Wachowiak ${ }^{2} \cdot$ Franciszek K. Główka $^{1}$
}

Published online: 19 March 2018

(C) The Author(s) 2018

\begin{abstract}
Treosulfan is a prodrug that undergoes a highly $\mathrm{pH}-$ and temperature-dependent nonenzymatic conversion to the monoepoxide $\{(2 \mathrm{~S}, 3 \mathrm{~S})-1,2$-epoxy-3,4-butanediol 4-methanesulfonate $[\mathrm{S}, \mathrm{S}-\mathrm{EBDM}]\}$ and diepoxide $\{(2 \mathrm{~S}, 3 \mathrm{~S})$ 1,2:3,4-diepoxybutane [S,S-DEB] \}. Currently, treosulfan is tested in clinical trials as an alternative to busulfan in conditioning prior to hematopoietic stem cell transplantation (HSCT). Of note, the optimal dosing of the prodrug is still unresolved, especially in infants. In this paper, the pharmacokinetics of treosulfan, together with its biologically active epoxides, is comprehensively reviewed for the first time, with the focus on conditioning prior to HSCT. Most of the insightful data presented in this review comes from studies that have been conducted in the last 3 years. The article widely discusses the volume of distribution and total clearance of treosulfan. In particular, the interindividual variability of these key parameters in infants, children above 1 year of age, and adults is analyzed, including possible covariates. A clinically important aspect of the formation rate-limited elimination of S,S-EBDM and S,SDEB is described, including the correlation between the exposure of the prodrug and S,S-EBDM in children. The
\end{abstract}

Electronic supplementary material The online version of this article (https://doi.org/10.1007/s40262-018-0647-4) contains supplementary material, which is available to authorized users.

Michał Romański

michalroman@ump.edu.pl

1 Department of Physical Pharmacy and Pharmacokinetics, Poznan University of Medical Sciences, 6 Święcickiego Street, 60-781 Poznan, Poland

2 Department of Pediatric Hematology, Oncology and Transplantology, Poznan University of Medical Sciences, 27/ 33 Szpitalna Street, 60-572 Poznan, Poland significance of the elimination half-life of treosulfan and its epoxides for successful conditioning prior to HSCT is also raised. Furthermore, the organ disposition of treosulfan and $\mathrm{S}, \mathrm{S}-\mathrm{EBDM}$ in rats is discussed in the context of the clinical toxicity and myeloablative activity of treosulfan versus busulfan. Moreover, perspectives for future therapeutic drug monitoring of treosulfan are presented. The review is intended to be helpful to pharmacists and doctors in the comprehension of the clinical pharmacokinetics of treosulfan.

\section{Key Points}

A highly $\mathrm{pH}-$ and temperature-sensitive nonenzymatic conversion to the active monoepoxide, glomerular filtration, and tubular reabsorption are involved in the elimination of the prodrug treosulfan.

To date, blood $\mathrm{pH}$, body temperature, and volume of intravenous infusions administered to HSCT patients have been neglected as the covariates of treosulfan clearance, but are worth testing.

The pharmacokinetics of the active epoxides of treosulfan are necessary to understand clinical observations in conditioning prior to HSCT. 


\section{Introduction}

Treosulfan, a water-soluble dihydroxy derivative of busulfan, is authorized in some European countries for the intravenous or oral treatment of advanced ovarian cancer. The intravenous regimen usually relies on drug doses of 5-8 g/ $\mathrm{m}^{2}$ administered every 3-4 weeks [1-3]. Moreover, for the last 17 years, high-dose treosulfan has been investigated worldwide as a myeloablative agent in conditioning regimens prior to hematopoietic stem cell transplantation (HSCT). In this therapy, patients receive $10-14 \mathrm{~g} / \mathrm{m}^{2}$ of the compound for 3 consecutive days. Retrospective analyses of clinical phase I and II trial results indicate that in both children and adults, treosulfan-based conditioning is associated with low-early hepato-, pulmo-, and neurotoxicity compared with busulfan-based treatment. On the other hand, the regimens containing the above drugs seem to exert comparable myeloablative, immunosuppressive, and antileukemic efficiency because the incidences of complete donor chimerism and malignancy relapse are similar [3-9].

In opposition to busulfan, treosulfan is a prodrug. At $\mathrm{pH}$ $>5$, it undergoes a nonenzymatic intramolecular nucleophilic substitution that sequentially leads to (2S,3S)-1,2epoxy-3,4-butanediol 4-methanesulfonate (S,S-EBDM) and then to (2S,3S)-1,2:3,4-diepoxybutane (S,S-DEB). These epoxy transformers are believed to account for the DNA alkylation and biological effects observed after administration of treosulfan [10-12].

Presently, prospective, multicenter, clinical phase II and III trials are ongoing that directly compare treosulfan versus busulfan in conditioning prior to allogeneic HSCT in children (1 month-18 years of age) with nonmalignant diseases, and in adults (18-70 years of age) with acute myeloid leukemia and myelodysplastic syndromes. In another ongoing phase III trial, treosulfan-based conditioning is compared not only with busulfan-based conditioning but also with fractionated total body irradiationbased conditioning in children and adolescents undergoing allogeneic HSCT for acute lymphoblastic leukemia, i.e. with the most frequent indication for HSCT in the pediatric population. The aim of the other prospective multicenter clinical phase II trial is to describe the safety and efficacy of treosulfan-based therapy in hematological malignancy pediatric patients ( 1 month-18 years of age) $[13,14]$. All these studies include pharmacokinetic evaluation to give precise recommendations on the optimal dosing of the prodrug prior to HSCT, which is yet unclear, particularly in children $[6-8,13,14]$. This issue warrants identifying all clinically relevant factors affecting the pharmacokinetic parameters of treosulfan, especially its total clearance $\left(\mathrm{Cl}_{\text {tot }}\right)$.
To date, only a few papers have briefly reviewed the clinical pharmacokinetics of sole treosulfan, most recently in 2014 [3-5]. Since that time, novel data have been reported that provided substantial insight into the topic. The data covered the kinetics of the nonenzymatic epoxy transformation of treosulfan, including the quantitative description of $\mathrm{pH}$ and temperature effect; the pharmacokinetics of S,S-EBDM in children; the discovery of the formation-rate pharmacokinetics of the epoxy transformers; the organ disposition of treosulfan and S,S-EBDM in rats; treosulfan population pharmacokinetics in humans; and studies on the association of treosulfan exposure with the toxicity and efficacy of HSCT conditioning $[10,11,15-25]$. This review is the first to be exclusively devoted to the pharmacokinetics of treosulfan and its epoxides. The main focus is given to the in-depth analysis of the pharmacokinetic parameters of treosulfan and S,SEBDM, and their significance for conditioning prior to HSCT. We discuss possible physiology- and treatment-related reasons of the interindividual variability of the compounds' $\mathrm{Cl}_{\mathrm{tot}}$ and volume of distribution, especially in children.

\section{Pharmacokinetics of the Prodrug Treosulfan}

\subsection{Overview}

The pharmacokinetics of treosulfan in HSCT patients has been investigated since the year 2000 using either a classic approach or population modeling. Besides two studies only, the disposition of treosulfan was described by an open two-compartmental model with first-order (linear) distribution and elimination [16, 21-29]. Ten Brink et al. [20] created a population pharmacokinetic model with onecompartmental drug disposition, but in the later study conducted in a larger cohort of patients, the model was refined to a two-compartmental model [24]. Moreover, Koyyalamudi et al. [30] applied a classic non-compartmental analysis. Table 1 shows the results from four major observational studies in which the pharmacokinetic parameters of treosulfan were determined individually in adult and pediatric patients treated with drug doses of $10-14 \mathrm{~g} / \mathrm{m}^{2}$. The population model estimates obtained in children are shown in Table 2.

\subsection{Volume of Distribution}

In the pharmacokinetic studies of treosulfan involving a classic two-compartment model, the so-called volume of drug distribution at steady state $\left(V_{\mathrm{ss}}\right)$ has been reported. The term 'steady state' used here means a transient state in which the drug concentration in a peripheral compartment 
Table 1 Pharmacokinetic parameters of TREO following an intravenous infusion to HSCT patients

\begin{tabular}{|c|c|c|c|c|c|c|c|c|c|}
\hline \multirow{3}{*}{$\begin{array}{l}\text { Group } \\
\text { First author } \\
\text { Patients [N (infants)] }\end{array}$} & \multicolumn{4}{|l|}{ Adults } & \multicolumn{5}{|l|}{ Children } \\
\hline & \multicolumn{2}{|c|}{ Beelen et al. [27] } & \multicolumn{2}{|c|}{ Nemecek et al. [28] } & \multicolumn{3}{|c|}{ Główka et al. [16] } & \multicolumn{2}{|c|}{$\begin{array}{l}\text { van der Stoep et al. } \\
{[24]}\end{array}$} \\
\hline & $8(0)$ & $10(0)$ & $4(0)$ & $12(0)$ & $3(0)$ & $4(1)$ & $7(0)$ & 12 (12) & $65(0)$ \\
\hline $\begin{array}{l}\text { Age, years [median or mean } \\
\text { (range)] }\end{array}$ & $\begin{array}{l}38 \\
(19-59)\end{array}$ & $\begin{array}{l}47 \\
(23-64)\end{array}$ & $\begin{array}{l}34 \\
\quad(18-47)\end{array}$ & $\begin{array}{l}34 \\
(5-55)^{\mathrm{a}}\end{array}$ & $\begin{array}{l}9.0 \\
\quad(2-13)\end{array}$ & $\begin{array}{l}5.5 \\
(0.4-10)\end{array}$ & $\begin{array}{l}14 \\
(2-18)\end{array}$ & $\begin{array}{l}0.90^{*} \\
(<1)\end{array}$ & $\begin{array}{l}8.0^{*} \\
(>1)\end{array}$ \\
\hline Dose, $\mathrm{g} / \mathrm{m}^{2}$ & 12 & 14 & 12 & 14 & 12 & 12 & 14 & 10 & 14 \\
\hline Infusion time, $\mathrm{h}$ & 2 & 2 & 2 & 2 & 1 & 2 & 2 & 3 & 3 \\
\hline PK analysis & \multicolumn{2}{|c|}{$\begin{array}{l}\text { Classic (two- } \\
\text { compartment } \\
\text { model) }\end{array}$} & \multicolumn{2}{|c|}{$\begin{array}{l}\text { Classic (two- } \\
\text { compartment } \\
\text { model) }\end{array}$} & \multicolumn{3}{|c|}{ Classic (two-compartment model) } & \multicolumn{2}{|c|}{$\begin{array}{l}\text { Population }{ }^{\mathrm{b}} \text { (two- } \\
\text { compartment } \\
\text { model) }\end{array}$} \\
\hline AUC, $\mathrm{mg} \times \mathrm{h} / \mathrm{L}(\%)$ & $898(12)$ & $1104(16)$ & $1365(21)$ & $\begin{array}{r}1309 \\
(20)\end{array}$ & $1050(6)$ & $1478(37)$ & $\begin{array}{r}2400 \\
(53)\end{array}$ & $1744(46)$ & $\begin{array}{r}1561 \\
(33)\end{array}$ \\
\hline $\mathrm{V}_{\mathrm{ss}}, \mathrm{L} / \mathrm{kg}$ or $\mathrm{L}^{*}(\%)$ & $34^{*}(15)$ & $31^{*}(23)$ & $17^{*}(25)$ & $22^{*}(17)$ & $0.78(10)$ & $0.56(34)$ & $\begin{array}{l}0.55 \\
(64)\end{array}$ & $0.21(62)$ & $\begin{array}{l}0.91 \\
(86)\end{array}$ \\
\hline $\mathrm{Cl}_{\text {tot }}, \mathrm{mL} / \mathrm{min} / \mathrm{kg}$ or $\mathrm{mL} / \mathrm{min}^{*}(\%)$ & $225^{*}(10)$ & $216^{*}(15)$ & $154^{*}(23)$ & $185^{*}(20)$ & $6.43(8)$ & $5.41(11)$ & $\begin{array}{l}4.07 \\
(39)\end{array}$ & $2.17(65)$ & $\begin{array}{l}8.08 \\
(62)\end{array}$ \\
\hline$t_{1 / 2}, h(\%)$ & $2.1(24)$ & $2.0(30)$ & $1.73(6)$ & $1.83(16)$ & $1.88(8)$ & $1.51(12)$ & $\begin{array}{l}2.06 \\
(10)\end{array}$ & No data & No data \\
\hline
\end{tabular}

$A U C$ area under the curve from time zero to infinity, $C l_{\text {tot }}$ total clearance, $P K$ pharmacokinetic, $t_{1 / 2}$ elimination half-life, $V_{s s}$ volume of distribution at steady state, TREO treosulfan, HSCT hematopoietic stem cell transplantation

Mean and coefficient of variation (in parentheses) are presented for all pharmacokinetic parameters

${ }^{a}$ Four children were included in the group (age 5-17 years)

${ }^{\mathrm{b}}$ Pharmacokinetic parameters were calculated from rich concentration-time curves in 29 patients and from 2 samples (limited samples strategy) in 48 patients

Table 2 Population pharmacokinetic parameters of TREO following an intravenous infusion to HSCT pediatric patients

\begin{tabular}{lllll}
\hline First author & Ten Brink et al. [20] & Danielak et al. [23] & van der Stoep et al. [24] & Chiesa et al. [21] \\
\hline Patients [N (infants)] & 20 (no data) & $15(1)$ & 77 (12) & 22 (6) \\
Age, years & $6.2 \pm 5.4$ (mean $\pm \mathrm{SD})$ & $7.8 \pm 4.9$ (mean \pm SD) & Median 4.8 (IQR 0.6-11.4) & Median 1.5 (range 0.08-14) \\
Dose, $\mathrm{g} / \mathrm{m}^{2}$ & 14 & 10,12 , or 14 & 10 or 14 & 10,12 , or 14 \\
Infusion time, $h$ & 3 & 1 or 2 & 3 & 2 \\
Disposition model & One-compartment & Two-compartment & Two-compartment & Two-compartment \\
$V_{\mathrm{ss}}, \mathrm{L} / \mathrm{kg}$ & 0.66 & 0.51 & 0.60 & 0.49 \\
$\mathrm{Cl}$ & $3.50(26)$ & $5.82(38)$ & 3.00 (no data) \\
\hline
\end{tabular}

$C l_{\text {tot }}$ total clearance, $C V$ coefficient of variation, IQR interquartile range, $S D$, standard deviation, $V_{s s}$ volume of distribution at steady state, $T R E O$ treosulfan, HSCT hematopoietic stem cell transplantation

${ }^{a}$ Extended model developed on the basis of the model by ten Brink et al. [20]

reaches its maximum, and the net rate of the drug transfer between the central and peripheral compartments amounts to zero. It is worth mentioning that the $V_{\mathrm{ss}}$ defined in this way is equivalent to the volume of distribution in a classic one-compartment model, and to the sum of the volumes of the central and peripheral compartments reported in population pharmacokinetic modeling. On average, the $V_{\mathrm{ss}}$ of treosulfan ranged from 17 to $34 \mathrm{~L}$ in adults (approximately $0.25-0.5 \mathrm{~L} / \mathrm{kg}$ ) and $0.5-0.6 \mathrm{~L} / \mathrm{kg}$ in children
$[16,21,23-28]$. To date, the binding of treosulfan to human plasma and tissue proteins has not been examined under physiological $\mathrm{pH}$ to avoid the epoxy transformation of the parent drug. However, it is worth noting that the drug recovery from acidified human plasma after $10 \mathrm{kDa}$ ultrafiltration cut-off was $96 \pm 4 \%$ [31], and its unbound fraction in acidified rat plasma and tissue homogenates exceeded $0.94[18,19]$. Moreover, the in vivo ratio of the area under the curve (AUC) of treosulfan in rat liver, lungs, 
muscle, and bone marrow to its AUC in plasma ranged from 0.8 to 1.0 [19]. The above properties, along with a nonelectrolyte character of treosulfan, provide indirect evidence for a very weak binding of the drug to plasma and tissue proteins. Moreover, the practically complete bioavailability of treosulfan in humans after oral administration, and its almost homogenous distribution in rat plasma, liver, lungs, and bone marrow, demonstrate that the drug easily crosses biological membranes, despite being hydrophilic (log of octanol/water partition coefficient $-1.58)[19,32,33]$. Based on the average values of the $V_{s s}$ of treosulfan (Tables 1 and 2), it may be concluded that the drug distributes into extracellular fluid and a part of intracellular fluid. As the percentage of total body water (TBW) decreases with age from birth ( 75\% in neonates, $\sim 60 \%$ at age $1-17$ years, $\sim 45 \%$ at age 64 years $)$, the highest values of the treosulfan $V_{\mathrm{ss}}(\mathrm{L} / \mathrm{kg})$ are expected in infants and the lowest in the elderly [34-36]. This hypothesis contrasts with the results obtained by van der Stoep et al. [24] using a population pharmacokinetic model (mean $V_{\mathrm{ss}}: 0.21 \mathrm{~L} / \mathrm{kg}$ in infants and $0.91 \mathrm{~L} / \mathrm{kg}$ in older children). Further studies are needed to reveal the reasons for the above discrepancy.

\subsection{Clearance and Systemic Exposure}

\subsubsection{Routes of Treosulfan Elimination and Clearance Estimation}

The fraction of unchanged treosulfan excreted in patients' urine $\left(f_{\mathrm{R}} ; 15-40 \%\right)$ and analysis of the in vitro kinetic results demonstrate that the $\mathrm{Cl}_{\text {tot }}$ of the prodrug has two clinically significant components: the clearance of S,SEBDM formation $\left(\mathrm{Cl}_{\mathrm{f}}\right)$ in the body fluids (major component), and the renal clearance of unchanged treosulfan $\left(\mathrm{Cl}_{\mathrm{R}}\right.$; minor component $)$ [Fig. 1]. In a clinical setting, $\mathrm{Cl}_{\mathrm{f}}$ may be determined indirectly as $\mathrm{Cl}_{\text {tot }}-\mathrm{Cl}_{\mathrm{R}}$ or $\mathrm{Cl}_{\text {tot }} \times\left(1-f_{\mathrm{R}}\right)$, based on the treosulfan concentration in plasma and its amounts in urine [10, 17, 26-29, 31]. Following basic pharmacokinetic concepts, it might be predicted that the $\mathrm{Cl}_{\mathrm{f}}$ of treosulfan depends on the rate constant of the S,S-EBDM formation from the prodrug $\left(k_{\mathrm{f}}\right)$ and the volume of fluids in which this process occurs. Noteworthy, the $k_{\mathrm{f}}$ itself has been found to be very sensitive to $\mathrm{pH}$ and temperature $[11,15]$. It is also known that at physiological conditions, the $\mathrm{pH}$ of the extracellular fluid, including blood, is tightly regulated at approximately 7.4, whereas the intracellular fluid may have a $\mathrm{pH}$ in a much wider range of 6.8-7.3, depending on the tissue type $[37,38]$. In theory, the $\mathrm{Cl}_{\mathrm{f}}$ could still be calculated by summing the products of the $k_{\mathrm{f}}$ in different body fluids and their volumes, according to

$\mathrm{Cl}_{\mathrm{f}}=\sum k_{\mathrm{f}} \times V$.

However, this is not feasible in a clinical setting. A surrogate method for $\mathrm{Cl}_{\mathrm{f}}$ estimation is to use a product of the $V_{\mathrm{ss}}$ of treosulfan and the $k_{\mathrm{f}}$ corresponding to the average $\mathrm{pH}$ of body fluids and $37{ }^{\circ} \mathrm{C}$. For that purpose, the $k_{\mathrm{f}}$ value can be calculated from the equation that was established for the nonenzymatic conversion of treosulfan to S,S-EBDM in buffer solutions at $37{ }^{\circ} \mathrm{C}$

$\log k_{\mathrm{f}}=-7.479+0.960 \times \mathrm{pH}$

$[10,11,17]$. Application of this approach, with the average $\mathrm{pH}$ of 7.35 , enables to predict the $\mathrm{Cl}_{\mathrm{f}}$ with good accuracy (error rate $<20 \%$ ) in 10 of 12 pharmacokinetic datasets reported previously for children above 1 year of age, as well as adults (electronic supplementary Table S1).

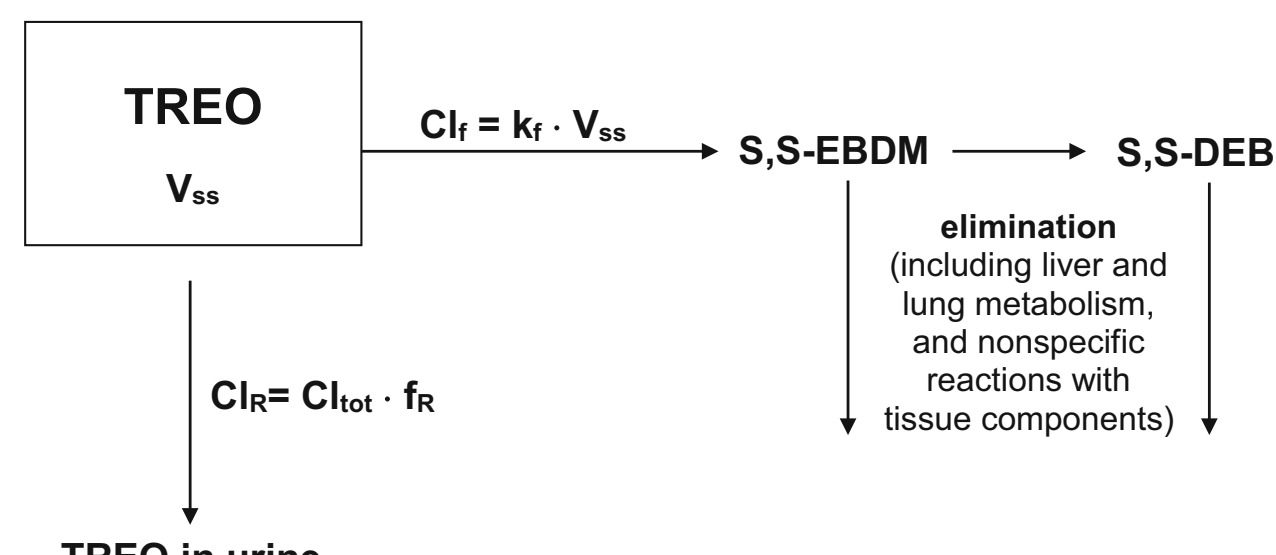

TREO in urine

Fig. 1 The scheme of the clinically significant routes of TREO elimination. $C l_{f}$ formation clearance, $C l_{R}$ renal clearance $C l_{\text {tot }}$ total clearance, $f_{R}$ fraction of TREO excreted in urine, $k_{f}$ rate constant of $\mathrm{S}, \mathrm{S}-\mathrm{EBDM}$ formation from TREO at average $\mathrm{pH}$ of the body fluids,
$V_{s s}$ volume of distribution at steady state, S,S-EBDM (2S,3S)-1,2epoxy-3,4-butanediol 4-methanesulfonate, S,S-DEB (2S,3S)-1,2:3,4diepoxybutane, TREO treosulfan 
To date, some studies have examined the $f_{\mathrm{R}}$ but did not focus on the mechanisms of renal excretion [26-29, 31]; however, the published data enable to indirectly deduce on the processes that are involved in the urinary elimination of the prodrug. Reviewing the paper by Hilger et al. [31], we found that in 28 women with ovarian cancer who received a single dose of 8 or $10 \mathrm{~g} / \mathrm{m}^{2}$ of the prodrug, the ratio of the $\mathrm{Cl}_{\mathrm{R}}$ of treosulfan $\left(f_{\mathrm{R}} \cdot \mathrm{Cl}_{\text {tot }}\right)$ to the clearance of creatinine was $0.41 \pm 0.22$ (mean \pm standard deviation). Moreover, in adult and pediatric HSCT patients, the estimates of the $\mathrm{Cl}_{R}$ ranged from 39 to $88 \mathrm{~mL} / \mathrm{min}$ and $10-104 \mathrm{~mL} / \mathrm{min}$, respectively (electronic supplementary Table S1) [26-29]. Bearing in mind the weak binding of treosulfan to plasma proteins, one may conclude from the above data that after glomerular filtration the prodrug undergoes a marked tubular reabsorption $(\sim 60 \%)$, which would confirm that treosulfan easily penetrates across biological membranes.

\subsubsection{Changes of the Total Clearance $\left(\mathrm{Cl}_{\text {tot }}\right)$ of Treosulfan with Age}

It is known that, compared with adults, children have large liver and kidneys relative to body weight (BW). On the other hand, the organs are functionally immature in neonates and younger infants [39, 40]. In particular, glomerular filtration rate reaches an adult level by 3-6 postnatal months, whereas tubular reabsorption is not fully developed until approximately 2 years of age [34, 35, 40]. Therefore, many drugs have higher $\mathrm{Cl}_{\text {tot }}$ per kilogram of BW in children above 1 year of age than in infants and adults. The available literature data indicate that treosulfan behaves likewise (Tables 1 and 2) [16, 21-29]. The changes of glomerular filtration and tubular reabsorption in the developing body most likely affect the $\mathrm{Cl}_{\mathrm{R}}$ of treosulfan but are insufficient to fully elucidate the observed agerelated variability in the drug $\mathrm{Cl}_{\text {tot }}$. The second important aspect that ought to be taken into consideration is the body fluids in which the nonenzymatic conversion of treosulfan to S,S-EBDM occurs. As blood $\mathrm{pH}$ in children does not differ from adults, one may take a reasonable assumption that the average $\mathrm{pH}$ of the body fluids, and consequently the average $k_{\mathrm{f}}$, have the same values in both groups. Accordingly, the higher $V_{\mathrm{ss}}$ of treosulfan observed in children is supposedly responsible for the higher drug $\mathrm{Cl}_{\mathrm{f}}$, which in turn contributes to the higher $\mathrm{Cl}_{\text {tot }}$ (the sum of $\mathrm{Cl}_{\mathrm{f}}$ and $\left.\mathrm{Cl}_{\mathrm{R}}\right)[10,16,17,21-29]$. The reason children $>1$ year of age (average treosulfan $\mathrm{Cl}_{\text {tot }} 3-6 \mathrm{~mL} / \mathrm{min} / \mathrm{kg}$ ) experience a similar AUC as adults (approximate $\mathrm{Cl}_{\text {tot }}$ $2.0-2.5 \mathrm{~mL} / \mathrm{min} / \mathrm{kg}$ ) following the same drug dosing per $\mathrm{m}^{2}$ of body surface area (BSA) is that the BW increases unproportionally faster with age than the BSA. As a result, pediatric patients receive higher doses of treosulfan per kilogram of BW than adults [16, 21-29, 41].
It has been claimed that the low $\mathrm{Cl}_{\text {tot }}$ of treosulfan in infants compared with older children stems from a low glomerular filtration rate, yet no relevant correlation has been found [22]. Because the treosulfan epoxy transformation is $\mathrm{pH}$-sensitive and is associated with the release of strong methanesulfonic acid, the renal processes involved in acid-base homeostasis are worth considering in terms of the prodrug $\mathrm{Cl}_{\mathrm{f}}[10,11]$. Of note, bicarbonate reabsorption and acid excretion in the neonatal kidney are much lower than in older children and adults. At the same time, neonates must excrete approximately $2-3 \mathrm{mmol}$ of $\mathrm{H}^{+}$per kilogram of BW daily in the form of ammonia and titratable acids, which is much more than in adults $(1 \mathrm{mmol} / \mathrm{kg})$. As a result, neonates often develop mild metabolic acidosis and have a limited capability to withstand additional stress, in particular acid load. Above 1 postnatal month, blood $\mathrm{pH}$ reaches adult values, but the renal control of acid-base balance continues to mature until approximately 2 years of age [34, 42-44]. One may estimate that if treosulfan was administered to an infant with a BW of $7.5 \mathrm{~kg}$ and BSA of $0.4 \mathrm{~m}^{2}$, at a dose of $4 \mathrm{~g}\left(10 \mathrm{~g} / \mathrm{m}^{2}\right)$, and was converted completely to S,S-DEB, the substantial load of $3.8 \mathrm{mmol}$ of $\mathrm{H}^{+}$(methanesulfonic acid) per kilogram of BW would be additionally produced in the body. Therefore, a hypothesis might be offered that infants treated with highdose treosulfan prior to HSCT are more prone to experience a lower blood $\mathrm{pH}$, as well as other body fluids, than older children, and, consequently, the decreased $\mathrm{Cl}_{\mathrm{f}}$ and $\mathrm{Cl}_{\text {tot }}$ of the prodrug. Such a phenomenon has not been reported to date but warrants verification in clinical observational studies.

\subsubsection{Stratification of Treosulfan Dose in Relation to Differences in $\mathrm{Cl}_{\text {tot }}$}

The age-related differences in the $\mathrm{Cl}_{\text {tot }}$ of treosulfan have found reflection in the stratification of the drug doses prior to HSCT. Currently, it seems that adults and older children undergoing HSCT against malignant diseases should be treated with $14 \mathrm{~g} / \mathrm{m}^{2}$ of treosulfan. Younger patients should receive lower doses to experience the same exposure as older patients, but a detailed dosing regimen is still ambiguous [7, 8, 21, 22, 24]. Van den Berg et al. [22] proposed the dose stratification based on the BSA: 10, 12, and $14 \mathrm{~g} / \mathrm{m}^{2}$ for patients with BSA $\leq 0.5,0.5-1.0$, and $>1.0 \mathrm{~m}^{2}$, respectively. In the study by Chiesa et al. [21], treosulfan was administered according to age: $10 \mathrm{~g} / \mathrm{m}^{2}$ ( $<3$ months), $12 \mathrm{~g} / \mathrm{m}^{2}$ (3 months -1 year), and $14 \mathrm{~g} / \mathrm{m}^{2}$ ( $>1$ year). As a result, 17 of 22 children had an AUC range of $1130-2451 \mathrm{mg} \cdot \mathrm{h} / \mathrm{L}$, including $4 / 4$ and $5 / 6$ infants receiving the lowest and middle doses, respectively [21]. In the remaining five patients, treosulfan AUC was much more scattered, with the lowest and highest value of 659 
and $\sim 4300 \mathrm{mg} \mathrm{h} / \mathrm{L}$, respectively. More recently, van der Stoep et al. [24] have reported the pharmacokinetic parameters obtained in 77 children following a two-level, age-based dose stratification: $10 \mathrm{~g} / \mathrm{m}^{2}$ below 1 year of age $(n=12)$ and $14 \mathrm{~g} / \mathrm{m}^{2}$ for higher ages $(n=65)$. They also observed a marked interpatient variability of treosulfan exposure (Table 1), especially in the younger group of patients, in whom the AUC spanned from 732 to $3544 \mathrm{mg} \mathrm{h} / \mathrm{L}$ [24]. Such results indicate that the use of age as the only variable for dose selection may not provide uniform exposure of treosulfan in children.

\subsection{Elimination Half-Life}

The elimination half-life $\left(t_{1 / 2}\right)$ of treosulfan in children and adults is relatively short $(1.5-2.2 \mathrm{~h})$ and does not demonstrate any age-related trend [16, 21, 26-29]. As the prodrug is administered to HSCT patients once daily for three consecutive days, no steady state (meant as equality between the dosing rate and the average drug elimination rate) is reached. Therefore, exposure could not be measured using an average concentration at steady state $\left(C_{\mathrm{ss}}\right)$, which is the case for busulfan administered four times daily $[3,5]$. It is worth noting that the short $t_{1 / 2}$ of treosulfan is beneficial in terms of its rapid elimination from the recipient's organism. In a rat model, the prodrug was eliminated from the brain two times slower than from blood and other organs, but the corresponding $t_{1 / 2}$ was still relatively short. Therefore, a washout period of at least 2 days, which is used after treosulfan administration in conditioning prior to HSCT, can be considered sufficient to prevent the graft from drug exposure [19].

\section{Factors Affecting Interindividual Variability of Volume of Distribution at Steady State and $\mathrm{Cl}_{\text {tot }}$ of Treosulfan}

As presented in Tables 1 and 2, the $V_{\text {ss }}$ and $\mathrm{Cl}_{\text {tot }}$ of treosulfan reported in children undergoing HSCT were characterized by relatively high interpatient variability, especially in the recent large multicenter study by van der Stoep et al. (coefficient of variation up to 86\%) [24]. Lower variability of the parameters was observed in the cohorts of adult patients, but, interestingly, quite marked differences occurred between the clinical centers [16, 22-29].

In attempts to identify the factors affecting the $V_{\text {ss }}$ and $\mathrm{Cl}_{\text {tot }}$ of treosulfan and their interindividual variability, population pharmacokinetic models were developed [20-25]. Van den Berg et al. [22] used pharmacokinetic data from 93 adults and 23 children (0.4-17 years of age), including a few infants (exact number was not given). Among BSA, age, BW, height, renal function, and use of diuretics, only BSA was found to be a covariate for the volume of the central compartment $\left(V_{1}\right)$, volume of the peripheral compartment $\left(V_{2}\right)$, and $\mathrm{Cl}_{\text {tot }}$ of treosulfan. The BSA allometric scaling factor for $\mathrm{Cl}_{\text {tot }}$ was equal to 1.29 $\left(\mathrm{Cl}_{\mathrm{tot}} \sim \mathrm{BSA}^{1.29}\right)$ [22]. In the four other models, the parameters were allometrically scaled using $\mathrm{BW}$, and the scaling exponents were fixed at 1.0 for both $V_{1}$ and $V_{2}$, and 0.75 for $\mathrm{Cl}_{\text {tot }}[20,21,23,24]$. In addition, Danielak et al. [23] found that sex was not a significant covariate for $V_{1}$, $V_{2}$, and $\mathrm{Cl}_{\text {tot }}$, however they noted that the studied group included only three girls. Ten Brink et al. [20] and van der Stoep et al. [24] did not mention testing any covariates, except BW. Surprisingly, in the model developed by Mohanan et al. [25], none of the covariates tested, i.e. age, BW, BSA, sex, liver size, liver fibrosis, ferritin levels, liver enzymes, and hemoglobin level, were found to explain the wide interindividual variability of treosulfan pharmacokinetics in thalassemia major patients aged 1.5-25 years. Despite age, renal function (creatinine clearance), and administration of diuretics not being identified as significantly influencing the $V_{\text {ss }}$ and $\mathrm{Cl}_{\text {tot }}$ of treosulfan [22, 23], these factors should not be neglected in future population pharmacokinetic modeling in larger and more homogeneous cohorts of HSCT patients. In particular, age may prove to be a significant variable in a sufficiently numerous cohort including young infants and children because of dynamic changes in the percentage of TBW and renal function occurring during the first postnatal year.

In our opinion, additional covariates worth testing in treosulfan pharmacokinetic modeling are blood $\mathrm{pH}$, as a readily measurable marker of acid-base balance, body temperature, and the volume of fluids infused intravenously to patients.

According to Eq. 2, the physiological fluctuations of blood $\mathrm{pH}$ from 7.35 to 7.45 are associated with a $24 \%$ increase in the $\mathrm{k}_{\mathrm{f}}\left(0.38-0.47 \mathrm{~h}^{-1}\right.$ at $\left.37^{\circ} \mathrm{C}\right)$. Greater changes of the $k_{\mathrm{f}}$ will obviously accompany acidosis or alkalosis [11]. A particularly high risk of developing metabolic acidosis is expected in infants withheld breastfeeding and thus deprived of the natural source of bases [43]. Moreover, in our previous work, we estimated that the body temperature change of only $1^{\circ} \mathrm{C}$ (from 36.5 to $37.5^{\circ} \mathrm{C}$ ) implicates an increase of $\mathrm{k}_{\mathrm{f}}$ by $17 \%\left(0.42-0.49 \mathrm{~h}^{-1}\right.$ at $\mathrm{pH}$ 7.4). Therefore, blood $\mathrm{pH}$ and body temperature might be valuable determinants of the $\mathrm{Cl}_{\mathrm{f}}$ and $\mathrm{Cl}_{\text {tot }}$ of treosulfan [15].

Following the widely accepted guidelines, children who undergo conditioning prior to HSCT in our department receive $3000 \mathrm{ml}$ of fluid per $\mathrm{m}^{2}$ of BSA daily, mainly $0.9 \%$ $\mathrm{NaCl}$ and $5 \%$ glucose supplemented with physiologically relevant amounts of potassium, magnesium, and calcium. This is associated with a continuous infusion halted only during the treosulfan infusion. Meanwhile, it has been 
found that during an intravenous infusion and several hours thereafter, the blood and extracellular fluid expand $[45,46]$. Hahn et al. [46] reported that at the end of 15- to 80-min infusions of Ringer's solution $25 \mathrm{~mL} / \mathrm{kg}$ BW administered to healthy adults, the volume of blood and extracellular fluid was increased by $20-25 \%$ and $\sim 10 \%$, respectively. When $12.5 \mathrm{~mL} / \mathrm{kg}$ of solution was infused over $30 \mathrm{~min}$, the blood expansion was $8 \%$ [46]. It is therefore possible that the $V_{\mathrm{ss}}$ of treosulfan in HSCT patients is artificially increased to an extent that depends on the load and infusion rates of the fluids. Whether this effect is clinically significant remains an open question. In our opinion, the fluid infusions should affect the $\mathrm{Cl}_{\mathrm{R}}$ of treosulfan. The general knowledge is that the large intravenous delivery of fluids provokes diuresis and thus diminishes the tubular reabsorption of drugs [45, 47]. As approximately one-half of treosulfan undergoes the reabsorption process, high-volume infusions should elevate the drug $\mathrm{Cl}_{\mathrm{R}}$ [31]. Concluding, the volume of fluids administered to HSCT patients on a daily basis might contribute to the interindividual variability of the $V_{\text {ss }}$ and/or $\mathrm{Cl}_{\text {tot }}$ of treosulfan, and also their differences between various clinical centers.

\section{Pharmacokinetics of Biologically Active Epoxy Derivatives of Treosulfan}

The results of the quantitative analysis of biologically active epoxy derivatives of treosulfan in patients' plasma were published for the first time in 2012 [48]. Following $2 \mathrm{~h}$ infusion of the prodrug at a dose of 12 and $14 \mathrm{~g} / \mathrm{m}^{2}$ to two children, the S,S-EBDM concentrations were approximately 100-fold lower than those of the parent compound, while the levels of S,S-DEB did not exceed the detection limit $(<0.8 \mu \mathrm{M})$ [48]. In the later study enrolling 16 pediatric patients, the $t_{1 / 2}$ of S,S-EBDM was found to not differ statistically from the parent drug [16]. The pharmacokinetics of S,S-EBDM and S,S-DEB remained unresolved until the preformed epoxides were administered to animals (rabbits) [17]. A very fast elimination of the compounds was then observed $\left(t_{1 / 2} \quad 0.069\right.$ and $0.046 \mathrm{~h}$, respectively), which was associated with the extremely high $\mathrm{Cl}_{\text {tot }}$ (167 and $233 \mathrm{~mL} / \mathrm{min} / \mathrm{kg}$, respectively). When treosulfan was administered to rabbits, the $t_{1 / 2}$ of $\mathrm{S}, \mathrm{S}$ EBDM did not differ statistically from that of the prodrug $(1.6 \mathrm{~h})$; likewise in the previous study in humans. Thus, it was proved that after administration of treosulfan, the elimination of its epoxides is limited by their formation from the parent compound (formation rate-limited kinetics). Consequently, the $t_{1 / 2}$ of S,S-EBDM and S,S-DEB is the same as that of treosulfan, despite the levels of epoxides in the body being very low compared with the prodrug due to their high $\mathrm{Cl}_{\text {tot }}$ [17]. Additional confirmation for this phenomenon was provided by an observation that the organ elimination of S,S-EBDM in rats proceeded at a similar rate as that of treosulfan (lungs, muscle, and bone marrow), except the brain, from which the epoxide was eliminated faster [19]. A clinical importance of the above facts is that once the elimination of treosulfan is completed, S,SEBDM and S,S-DEB are also eliminated from the patient's body. This is crucial for the graft protection in HSCT patients [17, 19].

The available data originating from in vitro and in vivo animal studies on the metabolites of 1,3-butadiene, including 1,2:3,4-diepoxybutane, suggest that the main elimination routes of the epoxy transformers of treosulfan are liver and lung metabolism via epoxide hydrolase and glutathione S-transferase, and nonspecific reactions with tissue components [49-51]. This is further supported by the immeasurable liver levels of S,S-EBDM in rats administered treosulfan, and the rapid elimination of the epoxy transformer from the lungs compared with the other organs [19]. To date, the $V_{\text {ss }}$ and $\mathrm{Cl}_{\text {tot }}$ of S,S-EBDM and S,S-DEB in humans have not been reported. A commonly known pharmacokinetic relationship, $\mathrm{AUC}_{\text {metabolite }} / \mathrm{AUC}_{\text {prodrug }}=$ $\mathrm{Cl}_{\mathrm{f}} / \mathrm{Cl}_{\text {metabolite, }}$ and the AUC data of treosulfan and S,SEBDM obtained in 16 pediatric patients prepared for HSCT, allow to indirectly estimate the $\mathrm{Cl}_{\text {tot }}$ of S,S-EBDM to be several hundred $\mathrm{mL} / \mathrm{min} / \mathrm{kg}[16,52]$. In these children, the AUC of S,S-EBDM correlated significantly with the AUC of the prodrug ( $p=0.022$ in the Spearman test), but the correlation coefficient was not high (0.57). This indicates that the S,S-EBDM to treosulfan AUC ratio can vary substantially between HSCT patients [16]. To investigate this issue, the development of a combined prodrugtransformer population pharmacokinetic model might be helpful. Apart from the covariates that were discussed for treosulfan $V_{\text {ss }}$ and $\mathrm{Cl}_{\text {tot }}$ in Sect. 3, it will be worth investigating liver function as a possible factor affecting the $\mathrm{Cl}_{\text {tot }}$ of S,S-EBDM [49, 50].

\section{Clinically Relevant Studies on the Organ Disposition of Treosulfan and S,S-EBDM in Rats}

The disposition of the prodrug and S,S-EBDM has been studied using a rat model to elucidate pharmacokinetic reasons underlying the organ toxicity of treosulfan. The liver/plasma, lungs/plasma, brain/plasma, and bone marrow/plasma AUC ratios obtained for treosulfan amounted to, on average, $0.96,0.82,0.10$, and 0.82 , respectively. These data demonstrated that the prodrug has similar capability to busulfan (AUC ratios 1.3, 1.0, 0.75, and 0.83, respectively) to distribute into the organs, except the brain. However, after scaling the tissue AUC results to the plasma 
drug concentrations of HSCT patients, which are two orders higher in the case of treosulfan, the exposure of all four organs to the prodrug turned out to be very high compared with busulfan (Table 3) [19]. This negated the hypothesis that the favorable organ toxicity of treosulfan might stem from the limited distribution of the prodrug into the respective tissues $[3,4,53]$. The levels of monoepoxide in the rat liver were unquantifiable. The average rat lungs/plasma, brain/plasma and bone marrow/plasma AUC ratios for biologically active S,S-EBDM were $0.50,0.35$, and 0.75 , respectively. After scaling the organ AUC results of S,S-EBDM to the concentrations observed in the plasma of HSCT patients, the clinical exposure of the lungs and brain to the epoxide was lower than to busulfan. On the other hand, the estimates of the AUC of S,S-EBDM and busulfan in patients' bone marrow were similar. These results provided a pharmacokinetic rationale for the clinical observations that treosulfan-based conditioning regimens demonstrate lower hepato-, pulmo-, and neurotoxicity than busulfan-based conditioning regimens, but comparable myeloablation strength [19].

The other study investigated the influence of very young age on the penetration of treosulfan and S,S-EBDM across the blood-brain barrier. Treosulfan was administered to 10and 34- to 35-day-old rats as they corresponded to neonates/younger infants and older children, respectively, in terms of blood-brain barrier functioning. The mean brainto-plasma treosulfan AUC ratio in younger and older animals was 0.16 and 0.08 , respectively, and the tissue/plasma AUC ratio obtained for S,S-EBDM was found to be 0.5 and 0.2 , respectively. These results led to the conclusion that very young patients receiving high-dose treosulfan prior to HSCT may experience higher neurotoxicity than older patients due to the increased penetration of the prodrug and S,S-EBDM across the incompletely mature blood-brain barrier. This corresponded to the results obtained in clinical studies in which seizures only occurred in patients under 4 months of age $[8,18]$.

\section{Perspectives for Therapeutic Drug Monitoring of Treosulfan}

Relatively high variability of treosulfan pharmacokinetics in pediatric patients may raise the need for implementing therapeutic drug monitoring and individual dose adjustment in this group. Since pharmacokinetic studies of treosulfan began, it has been assumed that plasma (serum) concentrations of the prodrug are a good representation of the alkylating activity of its epoxy transformers $[16,20,23-25,31]$. However, for years, a correlation between treosulfan concentrations in plasma and levels of specific DNA adducts in tissues, for example the bone marrow, or clinical effects, have not been investigated. Van der Stoep et al. [24] and Mohanan et al. [25] recently published the first results of a relationship between the exposure of treosulfan and early toxicity, as well as clinical outcome, in children undergoing conditioning prior to HSCT. In the former study, patients with an AUC $>1650 \mathrm{mg} \cdot \mathrm{h} / \mathrm{L}$ demonstrated a statistically higher incidence of mucosal and skin toxicity than those with an AUC $<1350 \mathrm{mg} \cdot \mathrm{h} / \mathrm{L}$ (odds ratio 4.4 and 4.5 , respectively). The odds of developing hepato- and neurotoxicity were also higher in the former group, but the difference did not reach statistical significance. No association was found between treosulfan exposure and early clinical outcomes, i.e. engraftment, donor chimerism, acute graft-versus-host disease, treatment-related mortality, and overall survival. The authors claimed that this might stem from the heterogeneity of patients' primary diseases, which were both malignant and nonmalignant [24]. However, in the later study [25] conducted exclusively in thalassemia major patients, no statistically significant relationship was found between the drug AUC and graft rejection, regimen-related toxicity, and treatment-related mortality. Compared with results reported by van der Stoep et al. [24], the data presented by Mohanan et al. [25] are somewhat conflicting with regard to survival outcomes only. In the thalassemia major children, Cox regression analysis demonstrated a statistically higher risk of poor overall and event-free

Table 3 Distribution of TREO, S,S-EBDM, and busulfan into the liver, lungs, brain, and bone marrow

\begin{tabular}{|c|c|c|c|}
\hline \multirow[t]{2}{*}{ Tissue } & \multicolumn{3}{|c|}{ Tissue/plasma AUC ratio in rats (estimated daily tissue AUC in HSCT patients $[\mu \mathrm{M} \cdot \mathrm{h}]$ ) } \\
\hline & $\mathrm{TREO}^{\mathrm{a}}$ & S,S-EBDM ${ }^{\mathrm{a}}$ & Busulfan \\
\hline Liver & $0.96-0.97(3072-7470)$ & Unquantifiable & $1.27^{\mathrm{b}}(76-127)$ \\
\hline Lungs & $0.82-0.83(2624-7470)$ & $0.46-0.53(7.4-48)$ & $1.05^{\mathrm{b}}(63-105)$ \\
\hline Brain & $0.10-0.11(320-990)$ & $0.34-0.36(5.4-32)$ & $0.75^{\mathrm{c}}(45-75)$ \\
\hline Bone marrow & $0.77-0.88(2463-7920)$ & $0.71-0.79(11-71)$ & $0.83^{\mathrm{b}}(50-83)$ \\
\hline
\end{tabular}

$A U C$ area under the curve from time zero to infinity, TREO treosulfan, S,S-EBDM (2S,3S)-1,2-epoxy-3,4-butanediol 4-methanesulfonate Data in the table are taken from Romański et al. [19] $]^{\mathrm{a}}$, Hassan et al. [54] , and Hassan et al. [55] ${ }^{\mathrm{c}}$ 
survival at low $\mathrm{Cl}_{\text {tot }}$ of treosulfan $\left(<8 \mathrm{~L} / \mathrm{h} / \mathrm{m}^{2}\right)$. Moreover, the Kaplan-Meier curve showed a trend towards better overall survival at high $\mathrm{Cl}_{\text {tot }}$ of treosulfan $\left(>8 \mathrm{~L} / \mathrm{h} / \mathrm{m}^{2}\right)$ and low AUC $(<1828 \mathrm{mg} \cdot \mathrm{h} / \mathrm{L})$, although without statistical significance [25]. Two hypotheses are worth considering and testing to explain the above results. The first is that a relatively low borderline AUC of treosulfan provides enough myeloablation for stable engraftment and acute graft-versus-host disease control, and also for overcoming a primary nonhematological disease, whereas the greater exposure intensifies both the antimalignancy effect and extramedullary toxicities. A second explanation might be the interindividual variability of the ratio of the systemic AUCs of S,S-EBDM and/or S,S-DEB to the prodrug (Sect. 4). Verification of this hypothesis warrants monitoring of the plasma concentrations of the treosulfan epoxy transformers, which are likely to better correlate with clinical results than those of the parent drug. At present, it seems that a relationship between treosulfan exposure and early regimen-related toxicity and clinical outcome is still unresolved. Investigations should be continued in larger disease-specific cohorts of HSCT patients. Ongoing studies will reveal how treosulfan exposure relates to long-term clinical outcomes and late toxicities, in particular gonadal function [23, 24].

As far as the future introduction of therapeutic monitoring of treosulfan is considered, it is worth mentioning that 2- or 3-point limited sampling strategies have been developed for determination of the drug AUC in HSCT children. They provided an accurate estimation of the exposure in all individual patients tested (error rate $<20 \%$ ), but the validation was performed in small groups (5-8 individuals). Therefore, the robustness of the above limited sampling strategies must be confirmed in larger cohorts before their use in routine practice [20, 23].

A challenge in therapeutic monitoring of treosulfan within conditioning prior to HSCT is a very brief course of treatment, consisting of three doses administered on 3 consecutive days. This allows personalization of only the second and third dose of the prodrug unless a test dose is applied prior to starting the actual regimen. The benefit of these two possible strategies will be worth examining in reference to fixed-dose conditioning in prospective studies if therapeutic monitoring comes into practice. To avoid artificial intercenter differences, the standardized protocols for treosulfan monitoring should be established, including blood sampling time, handling of the collected blood prior to bioanalysis, and mode of the AUC estimation (classic or population models). Moreover, the uniform mode of reporting volume of distribution and clearance should be implemented in terms of normalization to either $\mathrm{BW}$ or BSA. This is particularly essential in infants and children, who inherently demonstrate considerable anthropometric differences. Otherwise, the interpatient and intercenter comparisons of the pharmacokinetic parameters are problematic, or even senseless.

\section{Conclusions}

This holistic review of the currently available literature indicates that three processes contribute to the $\mathrm{Cl}_{\text {tot }}$ of treosulfan: glomerular filtration, tubular reabsorption, and nonenzymatic epoxy transformation of the prodrug. Therefore, blood $\mathrm{pH}$, body temperature, and intravenous fluid delivery should not be neglected as covariates of the $\mathrm{Cl}_{\text {tot }}$ of treosulfan in dose optimization efforts in HSCT patients, particularly infants. Organ disposition of treosulfan and S,S-EBDM in rats provides support for a lack of graft exposure to the compounds after at least a 2-day washout period preceding HSCT, the low organ toxicity of treosulfan-based conditioning compared with busulfanbased treatment, and the higher odds of neurological adverse effects in infants compared with older children. In terms of future therapeutic drug monitoring, larger studies are needed to verify the association of early and long-term toxicity and clinical outcomes with systemic exposure of not only treosulfan but also its active epoxy-transformers, at least S,S-EBDM.

\section{Compliance with Ethical Standards}

Funding Preparation of this manuscript was financially supported by the National Science Center in Poland (Grant number 2014/13/D/ NZ7/00278).

Conflicts of Interest Jacek Wachowiak receives fees from the pharmaceutical company medac $\mathrm{GmbH}$ for chairing the Data Monitoring Committee in two clinical studies on treosulfan. Michał Romański and Franciszek K. Główka declare that they have no conflicts of interest.

Open Access This article is distributed under the terms of the Creative Commons Attribution-NonCommercial 4.0 International License (http://creativecommons.org/licenses/by-nc/4.0/), which permits any noncommercial use, distribution, and reproduction in any medium, provided you give appropriate credit to the original author(s) and the source, provide a link to the Creative Commons license, and indicate if changes were made.

\section{References}

1. Sehouli J, Tomè O, Dimitrova $\mathrm{D}$, Camara $\mathrm{O}$, Runnebaum IB, Tessen HW, et al. A phase III, open label, randomized multicenter controlled trial of oral versus intravenous treosulfan in heavily pretreated recurrent ovarian cancer: a study of the NorthEastern German Society of Gynecological Oncology (NOGGO). J Cancer Res Clin Oncol. 2017;143:541-50. 
2. Treosulfan injection (medac UK): summary of product characteristics (SPC). Available at: https://www.medicines.org.uk/emc/ medicine/6431. Accessed 12 Dec 2017.

3. Galaup A, Paci A. Pharmacology of dimethanesulfonate alkylating agents: busulfan and treosulfan. Expert Opin Drug Metab Toxicol. 2013;9:333-47.

4. Główka FK, Romański M, Wachowiak J. High-dose treosulfan in conditioning prior to hematopoietic stem cell transplantation. Expert Opin Investig Drugs. 2010;19:1275-95.

5. Ten Brink MH, Zwaveling J, Swen JJ, Bredius RG, Lankester AC, Guchelaar HJ. Personalized busulfan and treosulfan conditioning for pediatric stem cell transplantation: the role of pharmacogenetics and pharmacokinetics. Drug Discov Today. 2014;19:1572-86.

6. Danylesko I, Shimoni A, Nagler A. Treosulfan-based conditioning before hematopoietic SCT: more than a BU look-alike. Bone Marrow Transplant. 2012;47:5-14.

7. Morillo-Gutierrez B, Beier R, Rao K, Burroughs L, Schulz A, Ewins AM, et al. Treosulfan-based conditioning for allogeneic HSCT in children with chronic granulomatous disease: a multicenter experience. Blood. 2016;128:440-8.

8. Slatter MA, Rao K, Abd Hamid IJ, Nademi Z, Chiesa R, Elfeky $\mathrm{R}$, et al. Treosulfan and fludarabine conditioning for hematopoietic stem cell transplantation in children with primary immunodeficiency: UK experience. Biol Blood Marrow Transplant. 2018;24(3):529-36.

9. Nagler A, Labopin M, Beelen D, Ciceri F, Volin L, Shimoni A, et al. Long-term outcome after a treosulfan-based conditioning regimen for patients with acute myeloid leukemia: A report from the Acute Leukemia Working Party of the European Society for Blood and Marrow Transplantation. Cancer. 2017;123:2671-9.

10. Romański M, Urbaniak B, Kokot Z, Główka FK. Activation of prodrug treosulfan at $\mathrm{pH} 7.4$ and $37^{\circ} \mathrm{C}$ accompanied by hydrolysis of its active epoxides: kinetic studies with clinical relevance. J Pharm Sci. 2015;104:4433-42.

11. Romański M, Ratajczak W, Główka F. Kinetic and mechanistic study of the $\mathrm{pH}$-dependent activation (epoxidation) of prodrug treosulfan including the reaction inhibition in a borate buffer. J Pharm Sci. 2017;106:1917-22.

12. Hartley JA, O'Hare CC, Baumgart J. DNA alkylation and interstrand cross-linking by treosulfan. Br J Cancer. 1999;79:264-6.

13. ClinicalTrials.gov. https://clinicaltrials.gov/ct $2 /$ results? cond= $\&$ term $=$ treosulfan \&cntry $1=\&$ state $1=\&$ recrs. Accessed 12 Dec 2017.

14. EU Clinical Trials Register. https://www.clinicaltrialsregister.eu/ ctr-search/search?query=treosulfan. Accessed 12 Dec 2017.

15. Romański M, Mikołajewski J, Główka FK. Effect of temperature on the kinetics of the activation of treosulfan and hydrolytic decomposition of its active epoxy derivatives. J Pharm Sci. 2017;106:3156-60.

16. Główka F, Kasprzyk A, Romański M, Wróbel T, Wachowiak J, Szpecht D, et al. Pharmacokinetics of treosulfan and its active monoepoxide in pediatric patients after intravenous infusion of high-dose treosulfan prior to HSCT. Eur J Pharm Sci. 2015;68:87-93.

17. Romański M, Kasprzyk A, Karbownik A, Szałek E, Główka FK. Formation rate-limited pharmacokinetics of biologically active epoxy transformers of prodrug treosulfan. J Pharm Sci. 2016;105:1790-7.

18. Romański M, Baumgart J, Böhm S, Główka FK. Penetration of treosulfan and its active monoepoxide transformation product into central nervous system of juvenile and young adult rats. Drug Metab Dispos. 2015;43:1946-54.

19. Romański M, Kasprzyk A, Walczak M, Ziółkowska A, Główka F. Disposition of treosulfan and its active monoepoxide in a bone marrow, liver, lungs, brain, and muscle: Studies in a rat model with clinical relevance. Eur J Pharm Sci. 2017;109:616-23.

20. Ten Brink MH, Ackaert O, Zwaveling J, Bredius RG, Smiers FJ, den Hartigh J, et al. Pharmacokinetics of treosulfan in pediatric patients undergoing hematopoietic stem cell transplantation. Ther Drug Monit. 2014;36:465-72.

21. Chiesa R, Winter R, Nademi Z, Standing J, Amrolia P, Veys P, et al. Pharmacokinetics of high dose intravenous treosulfan in children prior to allogeneic HCT [abstract no. PH-P584]. Bone Marrow Transplant. 2014;49(Suppl. 1):S380-1.

22. Van den Berg PJ, Ruppert M, Sykora K-W, Beier R, Beelen DW, Hilger RA, et al. A preliminary population pharmacokinetic model for dose selection of treosulfan used in conditioning treatment prior to haematopoietic stem cell transplantation (HSCT) in children [abstract PH-P543]. Bone Marrow Transplant. 2014;49(Suppl. 1):S360-1.

23. Danielak D, Twardosz J, Kasprzyk A, Wachowiak J, Kałwak K, Główka F. Population pharmacokinetics of treosulfan and development of a limited sampling strategy in children prior to hematopoietic stem cell transplantation. Eur J Clin Pharmacol. 2017;74:79-89.

24. Van der Stoep MYEC, Bertaina A, ten Brink MH, Bredius RG, Smiers FJ, Wanders DCM, et al. High interpatient variability of treosulfan exposure is associated with early toxicity in paediatric HSCT: a prospective multicentre study. $\mathrm{Br} \mathrm{J}$ Haematol. 2017;179:772-80.

25. Mohanan E, Panetta JC, Lakshmi KM, Edison ES, Korula A, Na $\mathrm{F}$, et al. Pharmacokinetics and pharmacodynamics of treosulfan in patients with thalassemia major undergoing allogeneic hematopoietic stem cell transplantation. Clin Pharmacol Ther. 2017. https://doi.org/10.1002/cpt.988.

26. Scheulen ME, Hilger RA, Oberhoff C, Casper J, Freund M, Josten KM, et al. Clinical phase I dose escalation and pharmacokinetic study of high-dose chemotherapy with treosulfan and autologous peripheral blood stem cell transplantation in patients with advanced malignancies. Clin Cancer Res. 2000;6:4209-16.

27. Beelen DW, Trenschel R, Casper J, Freund M, Hilger RA, Scheulen ME, et al. Dose-escalated treosulphan in combination with cyclophosphamide as a new preparative regimen for allogeneic haematopoietic stem cell transplantation in patients with an increased risk for regimen-related complications. Bone Marrow Transplant. 2005;35:233-41.

28. Nemecek ER, Guthrie KA, Sorror ML, Wood BL, Doney KC, Hilger RA, et al. Conditioning with treosulfan and fludarabine followed by allogeneic hematopoietic cell transplantation for high-risk hematologic malignancies. Biol Blood Marrow Transplant. 2011;17:341-50.

29. Główka FK, Karaźniewicz-Łada M, Grund G, Wróbel T, Wachowiak J. Pharmacokinetics of high-dose i.v. treosulfan in children undergoing treosulfan-based preparative regimen for allogeneic hematopoietic SCT. Bone Marrow Transplant. 2008;42:S67-70.

30. Koyyalamudi SR, Kuzhiumparambil U, Nath CE, Byrne JA, Fraser CJ, O'Brien TA, et al. Development and validation of a high pressure liquid chromatography-UV method for the determination of treosulfan and its epoxy metabolites in human plasma and its application in pharmacokinetic studies. J Chromatogr Sci. 2016;54:326-33.

31. Hilger RA, Harstrick A, Eberhardt W, Oberhoff C, Skorzec M, Baumgart J, et al. Clinical pharmacokinetics of intravenous treosulfan in patients with advanced solid tumors. Cancer Chemother Pharmacol. 1998;42:99-104.

32. Główka FK, Romański M, Siemiątkowska A. Determination of partition coefficients n-octanol/water for treosulfan and its epoxytransformers: an example of a negative correlation between lipophilicity of unionized compounds and their retention in 
reversed-phase chromatography. J Chromatogr B. 2013;923-924:92-7.

33. Hilger RA, Jacek G, Oberhoff C, Kredtke S, Baumgart J, Seeber $\mathrm{S}$, et al. Investigation of bioavailability and pharmacokinetics of treosulfan capsules in patients with relapsed ovarian cancer. Cancer Chemother Pharmacol. 2000;45:483-8.

34. Maples HD, James LP, Stowe CD. Special pharmacokinetic and pharmacodynamic considerations in children. In: Burton ME, Shaw LM, Schentag JJ, Evans WE, editors. Applied pharmacokinetics \& pharmacodynamics: principles of therapeutic drug monitoring. 4th ed. Philadelphia, PA: Lippincott Williams \& Wilkins; 2006. p. 216-8.

35. Fernandez E, Perez R, Hernandez A, Tejada P, Arteta M, Ramos JT. Factors and mechanisms for pharmacokinetic differences between pediatric population and adults. Pharmaceutics. 2011;3:53-72.

36. Chumlea WC, Guo SS, Zeller CM, Reo NV, et al. Total body water data for white adults 18 to 64 years of age: the Fels Longitudinal Study. Kidney Int. 1999;56:244-52.

37. Griffiths JR. Are cancer cells acidic? $\mathrm{Br} \mathrm{J}$ Cancer. 1991;64:425-7.

38. Gerweck LE, Seetharaman K. Cellular $\mathrm{pH}$ gradient in tumor versus normal tissue: potential exploitation for the treatment of cancer. Cancer Res. 1996;56:1194-8.

39. Mahmood I. Prediction of drug clearance in children from adults a comparison of several allometric methods. Br J Clin Pharmacol. 2006;61:545-57.

40. Chen N, Aleksa K, Woodland C, Rieder M, Koren G. Ontogeny of drug elimination by the human kidney. Pediatr Nephrol. 2006;21:160-8.

41. Sharkey I, Boddy AV, Wallace H, Mycroft J, Hollis R, Picton S. Body surface area estimation in children using weight alone: application in paediatric oncology. Br J Cancer. 2001;85:23-8.

42. Dell KM. Fluid, electrolytes, and acid-base homeostasis. In: Martin RJ, Fanaroff AA, Walsh MC, editors. Fanaroff and Martin's neonatal-perinatal medicine e-book: diseases of the fetus and infant, vol. 1. 10th ed. Philadelphia: Elsevier Saunders; 2015. p. 621-3.

43. Felver L. Fluid, electrolytes, and acid-base homeostasis. In: Copstead LEC, Banasik JL, editors. Phatophysiology. 5th ed. St. Louis: Elsevier Saunders; 2013. p. 539-48.
44. Quigley R, Baum M. Neonatal acid base balance and disturbances. Semin Perinatol. 2004;28:97-102.

45. Hahn RG. Volume kinetics for infusion fluids. Anesthesiology. 2010;113:470-81.

46. Hahn RG, Drobin D, Ståhle L. Volume kinetics of Ringer's solution in female volunteers. Br J Anaesth. 1997;78:144-1448.

47. Bryson PD. Methods of enhancing drug excretion. In: Bryson PD, editor. Comprehensive review in toxicology for emergency clinicians. 3rd ed. Washington, DC: Taylor \& Francis; 1996. p. $36-46$.

48. Główka FK, Romański M, Teżyk A, Żaba C, Wróbel T. HPLC method for determination of biologically active epoxy-transformers of treosulfan in human plasma: pharmacokinetic application. J Pharm Biomed Anal. 2012;62:105-13.

49. Boogaard PJ, Bond JA. The role of hydrolysis in the detoxification of 1,2:3,4-diepoxybutane by human, rat, and mouse liver and lung in vitro. Toxicol Appl Pharmacol. 1996;141:617-27.

50. Boogaard PJ, Sumner SCJ, Bond JA. Glutathione conjugation of 1,2:3,4-diepoxybutane in human liver and rat and mouse liver and lung in vitro. Toxicol Appl Pharmacol. 1996;136:307-16.

51. Sweeney LM, Schlosser PM, Medinsky MA, Bond JA. Physiologically based pharmacokinetic modeling of 1,3-butadiene, 1,2epoxy-3-butene, and 1,2:3,4-diepoxybutane toxicokinetics in mice and rats. Carcinogenesis. 1997;18:611-25.

52. Yang Z. In vivo metabolite kinetics. In: Nassar AF, Hollenberg PF, Scatina J, editors. Drug metabolism handbook: concepts and applications. New York: Wiley; 2009. p. 41-64.

53. Westerhof GR, Ploemacher RE, Boudewijn A, Blokland I, Dillingh $\mathrm{JH}, \mathrm{McGown}$ AT, et al. Comparison of different busulfan analogues for depletion of hematopoietic stem cells and promotion of donor-type chimerism in murine bone marrow transplant recipients. Cancer Res. 2000;60:5470-8.

54. Hassan M, Hassan Z, Nilsson C, Rehim MA, Kumlien S, Elfsson B, et al. Pharmacokinetics and distribution of liposomal busulfan in the rat: a new formulation for intravenous administration. Cancer Chemother Pharmacol. 1998;42:471-8.

55. Hassan M, Ehrsson H, Wallin I, Eksborg S. Pharmacokinetic and metabolic studies of busulfan in rat plasma and brain. Eur J Drug Metab Pharmacokinet. 1988;13:301-5. 